\title{
OCCIPITAL NEURALGIA CAUSED BY AN INTRAMUSCULAR LIPOMA. A CASE REPORT
}

Taluma Agnija, Griskjans Zans

Oral and Maxillofacial department in Pauls Stradinš̌ Clinical University Hospital

\begin{abstract}
Summary
Occipital neuralgia is a type of chronic headache disorder in the dermatomes of the greater or lesser occipital nerve. (7) We describe here a rare case of occipital neuralgia caused by an intramuscular lipoma. A 45 year- old man presented with troublesome pain in the occipital area with $3 \times 2 \mathrm{~cm}$ palpable mass in the right occipital region. Patient was treated by a neurologist. The $X$ ray for cervical vertebrae and computed tomography was performed.

Computed tomography revealed a mass reminding intramuscular lipoma. Surgical management was indicated. During the operation stretching of the lesser occipital nerve was detected. After resection of lipoma on postoperative follow - up, the patient reported that the pain had resolved. During the histopathological examination, lipoma was confirmed.
\end{abstract}

Keywords: occipital neuralgia, lipoma

\section{AIM}

Our aim is to present rare case of neuralgia caused by intramuscular lipoma in right occipital region

\section{INTRODUCTION}

Lipoma is a benign fat-based lesion of mesenchymal origin which can occur in any part of the human body. The most common supraclavicular location is the posterior neck, with the anterior or lateral neck and the supraclavicular fossa also being frequent sites. Macroscopically lesion has well defined borders; it is moveable and smooth in consistency. (1) Usually lipomas are asymptomatic masses, but in particular cases and localizations in the head and neck region there may be a variety of symptoms: pain, neuralgia, dysphagia, throat and neck movement discomfort, etc. Once fat is in lipoma it could not be utilized by the body; thus, when one loses weight, lipoma will not shrink. Thus, treatment is solely surgical. According to ICHD -III classification occipital neuralgia is unilateral or bilateral paroxysmal, shooting or stabbing pain in the posterior part of the scalp, in the distribution of the greater, lesser and/or third occipital nerves, sometimes accompanied by diminished sensation or dysaesthesia in the affected area. Commonly associated with tenderness over the involved nerve. (6), (2)

On imaging lipoma is well defined lesion without any infiltration to additional structures. Initially for diagnostic purposes, an ultrasonography (USG) is performed. For differential diagnosis and neighbouring structures evaluation computed tomography (CT) or magnetic resonance imaging (MRI) is done. (1) Histologically lipoma is composed of adipocytes that are identical to adult fat.

\section{CASE REPORT}

A 45-year-old male patient came to our department with complaints about neck pain and headaches in left occipital region for 2 years. The pain was severe in intensity, shooting and stabbing, irradiating to the frontal region. During this period, the patient was treated by a neurologist with Gabapentin and Amitriptyline medicaments. The pain relief was not satisfactory. Pain was eased temporarily by local anaesthetic block. Neuralgia continued and patient was referred to an oral and maxillofacial surgeon. On examination, approximately $3 \times 2 \mathrm{~cm}$ smooth mass in right occipital region was palpated. Additionally CT was performed. On the CT, a tumour appeared as a well-defined hypodense intramuscular mass (Fig 1). Surgical treatment was indicated. An operation was made under general anaesthesia; the patient was in prone position, an incision through the skin and subcutaneous tissue was made, and a blunt dissection of the trapezoid muscle was performed to access the lesion. The lesion was visible and had well-defined borders. (Fig 2) After a full lesion evacuation and a local haemostasis operation, the wound was closed by layers. During the operation, a stretching of the lesser occipital nerve was detected. The nerve was not connected to the tumour; during the operation, it was retracted and left intact. After resection of lipoma on postoperative follow-up, the patient reported that the pain had resolved. Diagnosis was approved histologically.

\section{DISCUSSION}

Similar cases are described in the literature. Han et al. in 2016 described an occipital neuralgia case caused by intramuscular lipoma. Symptoms also revealed after complete resection of lesion. (2) Large intramuscular lipoma was described by Kogurel et al. in 2017. A patient with a large $6 \times 4$ mass in the right deep cervical muscles was presented. Presence of the lesion was accompanied with pain in neck and occipital region for one year. After complete resection of the tumour, symptoms were gone. (3) 
Najaf et al. in 2019 described three cases of symptomatic head and neck lipomas. One of these cases was huge lipoma in cervical region causing patient pain. After surgical removal of lipoma, symptoms decreased. (4) Despite the benign nature of the tumour, intramuscular lipomas could be recurrent because of occasional infiltrative nature of the lesion. A eomplete resection with part of the adjacent muscles is necessary in these cases. Sohn et al in 2010 described 4 cases of lipoma in sternocleidomastoid muscle resected with adjacent muscle structures. After a 6 months follow - up, there was not any evidence about a recurrence of the lesion. (5)

These cases and our case examples show that sometimes the cause of occipital neuralgia, or cephalgia could be benign intramuscular lipoma.

\section{Conflict of interest: None}

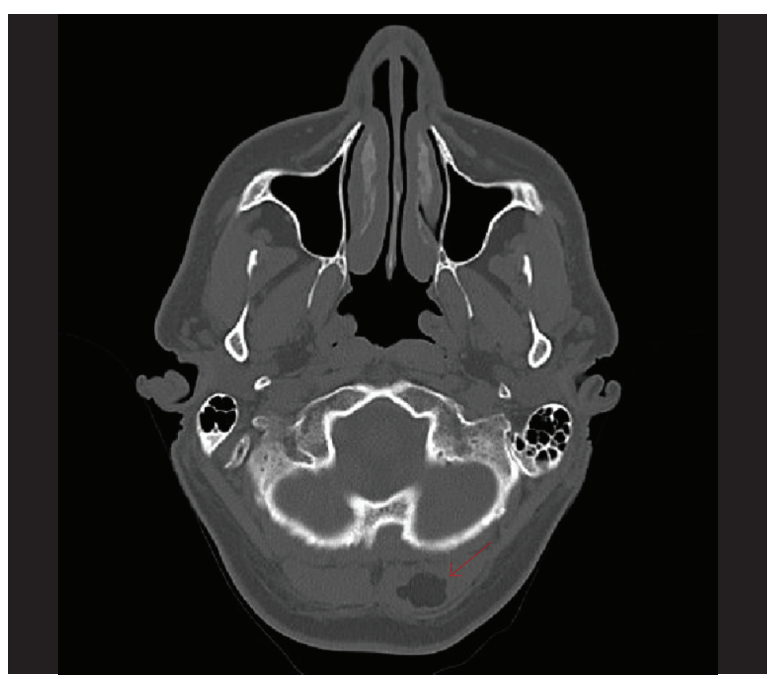

Fig. I CT shows well defined mass localized in left occipital region

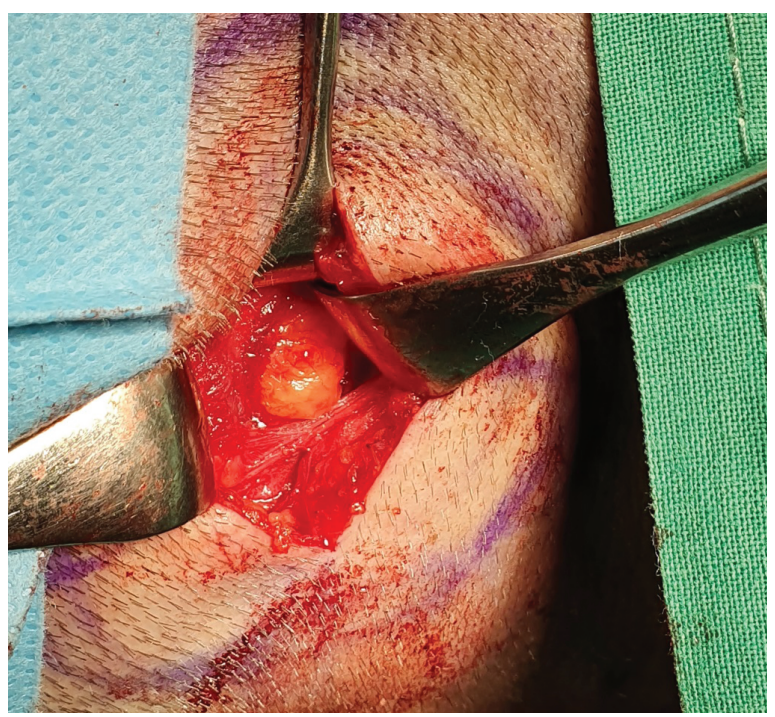

Fig. 2 Intraoperative view

\section{REFERENCES}

1. Delman BN, Weissman JL. , Som P.M. Skin and Soft-Tissue Lesions // In: Som P.M., Curtin HD, Head and Neck Imaging. $5^{\text {th }}$ ed. Elsevier Inc.: Mosby Inc.; 201 1; 2679-2742

2. Han HH, Kim HS, Rhie JW, Moon SH. Intramuscular Lipoma-Induced Occipital Neuralgia on the Lesser Occipital Nerve. J Craniofac Surg, 2016; 27(4): 350-352

3. Kogurel K, Yamazakil M, Tamakil T, Nodel Y, Morita A. Neck and Occipital Pain Caused by Deep Cervical Intramuscular Lipoma: A Surgical Case // J Nippon Med, 2017; 84: 96-99

4. Najaf Y, Cartier C, Favier V, Garrel R. Symptomatic head and neck lipomas // European Annals of Otorhinolaryngology, Head and Neck diseases, 2019; 136:127-129

5. Sohn WI, Kim JH, Jung SN, Kwon H, Cho KJ. Intramuscular lipoma of the sternocleidomastoid muscle. // J Craniofac Surg, 2010; 21(6):19761978

6. https://ichd-3.org/l3-painful-cranialneuropathies-and-other-facial-pains/13-4occipital-neuralgia/

7. Choi I, Jeon SR. Neuralgias of the Head: Occipital Neuralgia.//J Korean Med Sci, 2016; 31: 479-488

\section{Address:}

Agnija Taluma renai@inbox.lv

Zans Griskjans z.griskjans@gmail.com

Oral and Maxillofacial department in Pauls Stradinš̌ Clinical University Hospital 